\title{
Optimization of synthesis and characterization of nanosilica produced from rice husk (a common waste material)
}

\author{
Ezzat Rafiee $^{1 *}$, Shabnam Shahebrahimi ${ }^{1}$, Mostafa Feyzi $^{1}$ and Mahdi Shaterzadeh ${ }^{2}$
}

\begin{abstract}
Rice husk (RH), an inexpensive waste material, was used to produce nanosilica. Acid treatment of RH followed by thermal combustion under controlled conditions gave $22.50 \%$ ash of which $90.469 \%$ was silica. Various chemical treatments in varied conditions for controlled combustion were investigated in order to produce highly purified nanosilica. The structural properties (such as X-ray diffraction, Brunauer-Emmett-Teller, Fourier transform infrared spectroscopy, and transmission electron microscopy) of the silica were studied. The method was optimized, and the chemical composition of the product was determined by X-ray fluorescence and carbon, hydrogen, and nitrogen analysis. Lime reactivity of the ashes was determined. At optimized conditions, a nanosized, highly purified silica (98.8 mass percentage) was produced with a high surface area, high reactivity, and 99.9\% amorphous in form. Strength and number of acidic sites were measured by potentiometric titration. This nanosilica showed strong and a large number of acidic sites in comparison with commercial silica, making it as a good support for catalysts. This economic technology, as applied to waste material, also provides many benefits to the local agro-industry.
\end{abstract}

Keywords: Nanomaterial, Amorphous material, Nanosilica, Rice husk ash, Silica powder, Surface properties

\section{Background}

Rice is one of the major food crops in the world. Its production generates an equally great amount of waste in the world, namely rice husk (RH), a by-product of the multistage processing of rice. $\mathrm{RH}$ accounts for approximately one-fifth of the annual gross rice production in the world, which currently stands at 545 million metric tons [1]. Rice production constitutes a dominant agroindustry worldwide, where rice is the main food crop that is grown in the waterlogged semitropical areas. With such a large availability of raw materials, it becomes economical to make them as sources of more commercial applications. Presently, having no commercial value in itself, $\mathrm{RH}$ usually ends up being burned in open spaces, thus causing environmental pollution and disposal problems. Due to the need to conserve energy and resources, efforts have been made to burn the husk under controlled conditions and to utilize the resultant ash as building, semiconductor, composite, and abrasive

\footnotetext{
*Correspondence: ezzat_rafiee@yahoo.com

${ }^{1}$ Faculty of Chemistry, Razi University, Kermanshah 67149, Iran

Full list of author information is available at the end of the article
}

materials [2-5]. Also, ash is an active catalyst and a good material for catalyst support because of its high surface area [6].

The chemical composition of $\mathrm{RH}$ has been found to vary from sample to sample. Any of the differences in type of paddy, crop year, climatic and geographical conditions, soil chemistry, sample preparation, or method of analysis could be a reason for this variation. $\mathrm{RH}$ is an excellent source of high-grade silica [7-9]. The presence of silica in RH has been known since 1938 [10], ever since several efforts on preparation of silica from $\mathrm{RH}$ by researchers have been known internationally [11-18]. This kind of silica has been shown to be a good material for the synthesis of very pure silicon, silicon nitride, silicon carbide, magnesium silicide, and other applications $[6,9,19]$. Recently, nanotechnology has aroused considerable scientific interest because of new potential uses of particles on a nanometric scale. Thus, industries may be able to reengineer many existing products to function at unique levels. The production of reactive nanoscale silica from RH is a simple process compared to other conventional production techniques such as vapor phase 
reaction, sol-gel process, etc. [6,20-22]. The emphasis of this paper is to optimize the conditions for the preparation of highly purified rice husk ash (RHA), of which nanosilica is then extracted, and to study its properties. Also, the preparation of RHA has been optimized.

\section{Methods \\ Materials}

The raw material was obtained from a rice mill in the north of Iran. All reagents used were of analytical grade, and their solutions were made up in twice distilled, deionized water. $\mathrm{HCl}, \mathrm{H}_{2} \mathrm{SO}_{4}, \mathrm{HNO}_{3}, \mathrm{CH}_{3} \mathrm{COOH}, \mathrm{NaOH}$, $\mathrm{NH}_{4} \mathrm{OH}$, EDTA, $\mathrm{KOH}$, and $\mathrm{CaO}$ were of laboratory grade from Merck (Merck \& Co., Inc., Whitehouse Station, NJ, USA).

\section{Methods}

\section{Washing and acid treatment}

$\mathrm{RH}$ was washed thoroughly with water to remove the soluble particles, dust, and other contaminants present, whereby the heavy impurities such as sand are also removed. It was then dried in an air oven at about $110^{\circ} \mathrm{C}$ for $24 \mathrm{~h}$. The dried $\mathrm{RH}$ was refluxed with an acidic solution $\left(\mathrm{HCl}, \mathrm{HNO}_{3}\right.$, and $\mathrm{CH}_{3} \mathrm{COOH}$ in different concentrations) for nearly $90 \mathrm{~min}$ by stirring frequently. It was cooled and kept intact for about $20 \mathrm{~h}$. It was then decanted and thoroughly washed with warm distilled water until the rinse became free from acid, and this was designated as $\mathrm{RH}^{\prime}$. The wet $\mathrm{RH}^{\prime}$ was subsequently dried in an oven at $110^{\circ} \mathrm{C}$ for $24 \mathrm{~h}$.

\section{Thermal treatment}

A weighed $\mathrm{RH}^{\prime}$ as well as $\mathrm{RH}$ were subjected to heat treatment to obtain the ash. Samples were burned inside a programmable furnace (Nabertherm controller B 170, Nabertherm GmbH, Lilienthal, Germany), and different methods were applied. Different temperatures $\left(500^{\circ} \mathrm{C}\right.$, $700^{\circ} \mathrm{C}$, and $\left.1,000^{\circ} \mathrm{C}\right)$ and rates $\left(2^{\circ} \mathrm{C} / \mathrm{min}, 5^{\circ} \mathrm{C} / \mathrm{min}\right.$, and $10^{\circ} \mathrm{C} / \mathrm{min}$ ) were checked. We designated these as ashes (RHAs).

\section{Extraction of silica}

A sample of $20.0 \mathrm{~g}$ RHA was stirred in a $160-\mathrm{mL}, 2.5-\mathrm{M}$ sodium hydroxide solution. The solution was heated in a covered beaker for $3 \mathrm{~h}$ by stirring constantly and filtered; the residue was then washed with $40 \mathrm{~mL}$ of boiling distilled water. The obtained viscous, transparent, and colorless solution was allowed to cool down to room temperature, and $10 \mathrm{M} \mathrm{H}_{2} \mathrm{SO}_{4}$ was then added under constant stirring at controlled conditions until it reached $\mathrm{pH} 2 ; \mathrm{NH}_{4} \mathrm{OH}$ was added up to $\mathrm{pH} 8.5$ and was allowed to stand at room temperature for $3 \mathrm{~h}$.

\section{Preparation of nanosilica}

Nanosilica was prepared by reflux technique of the above extracted silica with $6.0 \mathrm{M} \mathrm{HCl}$ for $4 \mathrm{~h}$ and then washed repeatedly using deionized water to make it acid free. It was then dissolved in $2.5 \mathrm{M}$ sodium hydroxide by stirring. $\mathrm{H}_{2} \mathrm{SO}_{4}$ was added until it reached $\mathrm{pH}$ 8. The precipitate silica was washed repeatedly with warm, deionized water to make it alkali free and then dried at $50^{\circ} \mathrm{C}$ for $48 \mathrm{~h}$ in the oven.

\section{Characterization}

The silica content and the amount of metallic impurities in the samples were estimated by XRF Philips X-ray spectrometer (model PW 2404, Philips, Amsterdam, The Netherlands). Carbon, hydrogen, and nitrogen ( $\mathrm{CHN})$

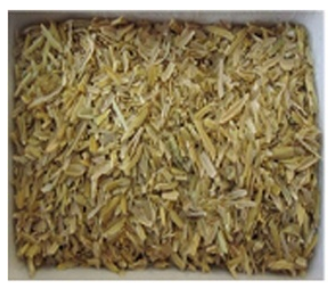

(a)

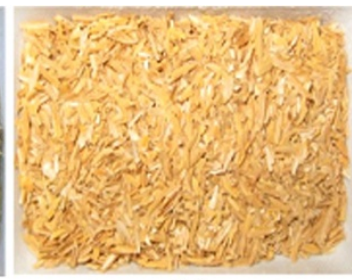

(b)

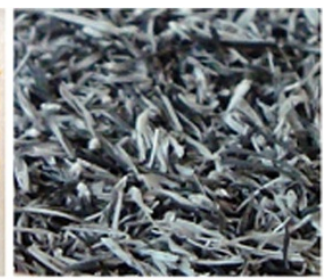

(c)

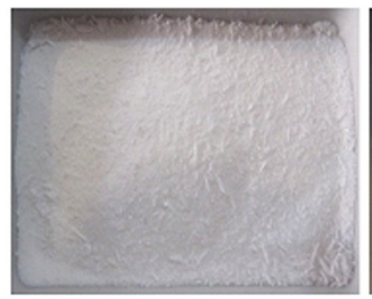

(d)

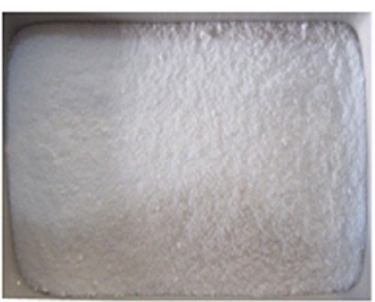

(e)

Figure 1 Different images of $\mathrm{RH}$ in different conditions. (a) $\mathrm{RH}$, (b) $\mathrm{RH}^{\prime}$, (c) $\mathrm{RHA}$ with combustion temperature of $500^{\circ} \mathrm{C}$, (d) $\mathrm{RHA}$ with combustion temperature of $700^{\circ} \mathrm{C}$, and (e) nanosilica. 
compositions were measured by HEKAtech elemental analysis (model Euro EA 3000, HEKAtech GmbH, Wegberg, Germany). Fourier transform infrared spectroscopy (FTIR) spectra were recorded with $\mathrm{KBr}$ pellets using a WQF-510 FTIR Rayleigh (Beijing Rayleigh Analytical Instruments Co., Ltd., Beijing, China). The X-ray diffraction (XRD) pattern of the sample was recorded on a Philips X'Pert $(40 \mathrm{kV}, 30 \mathrm{~mA})$ X-ray diffractometer (Philips, Amsterdam, The Netherlands). Scans were taken with a $2 \theta$ and a counting time of 1.0 s using a $\mathrm{Cu}-\mathrm{K} \alpha$ radiation source $(\lambda=1.542 \AA)$ and a nickel filter. The surface areas were calculated from the linear part of the Brunauer-Emmett-Teller (BET) plot. Low-temperature nitrogen adsorption experiments were performed using a Quantachrome instrument (model Nova 2000, Quantachrome Instruments, Boynton Beach, FL, USA) system for measuring the surface area and pore volume. Transmission electron microscopy (TEM) examination was performed using a TEM microscope Philips CM 120 kV (Philips, Amsterdam, The Netherlands). The RH samples were heated in a programmable furnace (Naberthem controller B 170, Nabertherm GmbH, Lilienthal, Germany). The potential variation was measured with a Jenway $3510 \mathrm{pH}$ meter (Jenway, Staffordshire, UK) and a double-junction electrode.

\section{Acidity measurement}

For potentiometric titration, $0.05 \mathrm{~g}$ of solid was suspended in acetonitrile $(90 \mathrm{~mL})$ and stirred for $3 \mathrm{~h}$. The suspension was titrated with a $0.05-\mathrm{M}$ solution of $n$-butylamine in acetonitrile. The potential variation was measured using a double-junction electrode.

\section{Lime reactivity}

The reactivity of the ash was determined according to a given chemical method [23]. Lime reactivity of the various ashes was determined by suspending a small quantity
Table 2 Lime reactivity values of RHA samples prepared at different conditions

\begin{tabular}{llllll}
\hline $\begin{array}{l}\text { Entry } \\
\text { acid }\end{array}$ & $\begin{array}{l}\text { Type of } \\
\text { (M) }\end{array}$ & $\begin{array}{l}\text { Concentration } \\
\left({ }^{\circ} \mathbf{C}\right)\end{array}$ & $\begin{array}{l}\text { Temperature } \\
\text { heating } \\
\text { ('C/min) }\end{array}$ & $\begin{array}{l}\text { Lime } \\
\text { reactivity } \\
\text { (mg CaO/g) }\end{array}$ \\
\hline 1 & $\mathrm{HCl}$ & 0.01 & 700 & 5 & 55.23 \\
2 & $\mathrm{HCl}$ & 0.1 & 700 & 5 & 58.72 \\
3 & $\mathrm{HCl}$ & 1.0 & 700 & 5 & 62.71 \\
4 & $\mathrm{HNO}_{3}$ & 0.01 & 700 & 5 & 54.15 \\
5 & $\mathrm{HNO}_{3}$ & 0.1 & 700 & 5 & 57.41 \\
6 & $\mathrm{HNO}_{3}$ & 1.0 & 700 & 5 & 61.39 \\
7 & $\mathrm{HOAC}$ & 0.1 & 700 & 5 & 50.81 \\
8 & $\mathrm{HOAC}$ & 1.0 & 700 & 5 & 55.30 \\
9 & $\mathrm{HOAC}$ & 5.0 & 700 & 5 & 59.75 \\
10 & $\mathrm{HCl}$ & 0.1 & 500 & 5 & 47.82 \\
11 & $\mathrm{HCl}$ & 1.0 & 500 & 5 & 51.56 \\
12 & $\mathrm{HCl}$ & 0.1 & 1,000 & 5 & 56.21 \\
13 & $\mathrm{HCl}$ & 1.0 & 1,000 & 5 & 58.16 \\
14 & $\mathrm{HCl}$ & 0.1 & 700 & 2 & 50.06 \\
15 & $\mathrm{HCl}$ & 1.0 & 700 & 2 & 59.42 \\
16 & $\mathrm{HCl}$ & 0.1 & 700 & 10 & 60.72 \\
17 & $\mathrm{HCl}$ & 1.0 & 700 & 10 & 64.27 \\
18 & $\mathrm{H} 2 \mathrm{O}$ & - & 700 & 5 & 56.16 \\
19 & $\mathrm{No} \mathrm{acid}$ & - & 700 & 5 & 37.73 \\
20 & $\mathrm{RH}$ & - & - & - & 12.00 \\
\hline & & & & & \\
\hline
\end{tabular}

(approximately $0.3 \mathrm{~g}$ ) of the ash in $50 \mathrm{~mL}$ of saturated lime solution at room temperature and by stirring after $18 \mathrm{~h}$. The unused $\mathrm{Ca}$ was estimated by titration with a 0.001-M EDTA solution.

\section{Results and discussion}

The metallic ingredients have a substantial effect on the quality of silica from $\mathrm{RH}$, which is mainly potassium that

Table 1 Specific surface area and pore volume of RHA produced at different conditions

\begin{tabular}{|c|c|c|c|c|c|c|}
\hline Entry & Type of acid & Concentration (M) & Rate of heating $\left({ }^{\circ} \mathrm{C} / \mathrm{min}\right)$ & Temperature $\left({ }^{\circ} \mathrm{C}\right)$ & Surface area $\left(\mathrm{m}^{2} / \mathrm{g}\right)$ & Pore volume $\left(\mathrm{cm}^{3} / \mathrm{g}\right)$ \\
\hline 1 & $\mathrm{HCl}$ & 0.01 & 5 & 700 & 111.60 & 0.00548 \\
\hline 2 & $\mathrm{HCl}$ & 0.1 & 5 & 700 & 139.80 & 0.00525 \\
\hline 3 & $\mathrm{HCl}$ & 1.0 & 5 & 700 & 151.20 & 0.00610 \\
\hline 4 & $\mathrm{HCl}$ & 1.0 & 10 & 700 & 153.10 & 0.00650 \\
\hline 5 & $\mathrm{HNO}_{3}$ & 0.1 & 5 & 700 & 129.80 & 0.00610 \\
\hline 6 & $\mathrm{HOAC}$ & 0.1 & 5 & 700 & 13.40 & 0.00567 \\
\hline 7 & $\mathrm{HCl}$ & 0.1 & 2 & 700 & 103.20 & 0.00498 \\
\hline 8 & $\mathrm{HCl}$ & 0.1 & 10 & 700 & 148.70 & 0.00602 \\
\hline 9 & $\mathrm{HCl}$ & 0.1 & 5 & 500 & 109.40 & 0.00587 \\
\hline 10 & $\mathrm{HCl}$ & 0.1 & 5 & 1,000 & 98.41 & 0.00532 \\
\hline 11 & $\mathrm{H}_{2} \mathrm{O}$ & - & 5 & 700 & 108.80 & 0.00600 \\
\hline
\end{tabular}


Table 3 Lime reactivity and chemical composition by X-ray fluorescence analysis

\begin{tabular}{llll}
\hline & RHA & Extracted silica & Nanosilica \\
\hline Color & White & White & White \\
$\mathrm{SiO}_{2}$ & 90.469 & 96.529 & 98.801 \\
$\mathrm{Na}_{2} \mathrm{O}$ & 0.630 & Trace & Trace \\
$\mathrm{K}_{2} \mathrm{O}$ & Trace & Trace & Trace \\
$\mathrm{MgO}$ & 0.050 & 0.038 & 0.020 \\
$\mathrm{CaO}$ & Trace & Trace & Trace \\
$\mathrm{Fe}_{2} \mathrm{O}_{3}$ & Trace & Trace & Trace \\
$\mathrm{Al}_{2} \mathrm{O}_{3}$ & 0.097 & Trace & Trace \\
$\mathrm{SO}_{3}$ & 0.153 & Trace & Trace \\
LOI & 8.600 & 2.333 & 1.179 \\
Lime reactivity (mg CaO/g) & 64.27 & 65.50 & 72.50 \\
\hline
\end{tabular}

causes surface melting and accelerates the crystallization of amorphous silica and carbon fixation in RHA. Also, a strong interaction occurs between the metallic ions and silica which leads to a considerable decrease in the surface area. Therefore, it is preferable to treat $\mathrm{RH}$ with an optimally acidic solution (such as $\mathrm{HCl}, \mathrm{HNO}_{3}$, or $\mathrm{CH}_{3} \mathrm{COOH}$ in varying concentrations) to effectively diminish impurities and to obtain highly purified silica powder. The decreased impurities result mainly from chemical reaction between acid and metals, and then the reacted metals are leached from the acidic solution during filtration. The change in color during digestion is also remarkable. The original brown color of the $\mathrm{RH}$ changes to yellowish and light yellow on increasing the time of digestion. Figure 1a,b shows the color of RH and $\mathrm{RH}^{\prime}$ (after leaching with $0.1 \mathrm{M} \mathrm{HCl}$ for $90 \mathrm{~min}$ ). The metals are also probably carried out from the volatiles during thermal decomposition. When burned, $\mathrm{RH}$ gives ash (RHA). If it is burned under controlled conditions, amorphous silica is produced, which is highly reactive in nature. The quality of RHA is dependent on various factors such as ashing temperature, time, rate of heating, and soaking time. The BET surface areas and pore volume of the produced RHA in different conditions are given in Table 1 . The effect of different chemical treatments for the removal of metallic ingredients shows that leaching with $1.0 \mathrm{M} \mathrm{HCl}$ is the best one for high surface area and pore volume. It should be noted that the RHA formed at a lower combustion temperature $\left(500^{\circ} \mathrm{C}\right)$ showed higher impurity and that at a higher temperature of combustion $\left(1,000^{\circ} \mathrm{C}\right)$, the crystallization of silica increased. Also, the specific surface area decreased with increasing temperature (Table 1). This decrease of $S_{\mathrm{BET}}$ can be attributed to the portion of the pores destroyed in the process. Amorphous silica of high purity and relatively high surface area was prepared at $700^{\circ} \mathrm{C}$. Rapid heating of $\mathrm{RH}$ does not allow the oxidation of carbon before the surface melting occurs, resulting in a higher amount of black particles. A good rate of heating was $10^{\circ} \mathrm{C} / \mathrm{min}$; in this condition, carbon formation and its oxidation occur before dissociation of metal oxides and (a)

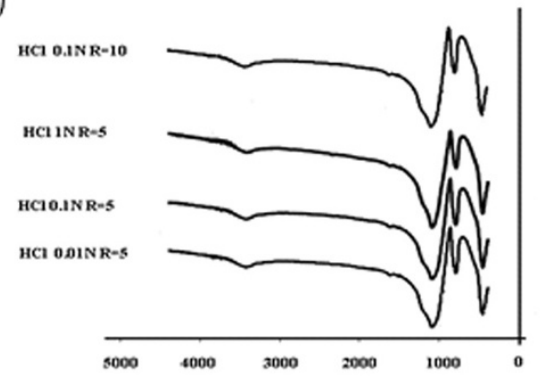

(c)

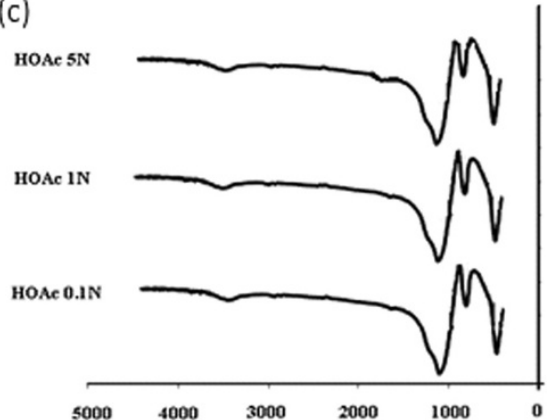

(b)

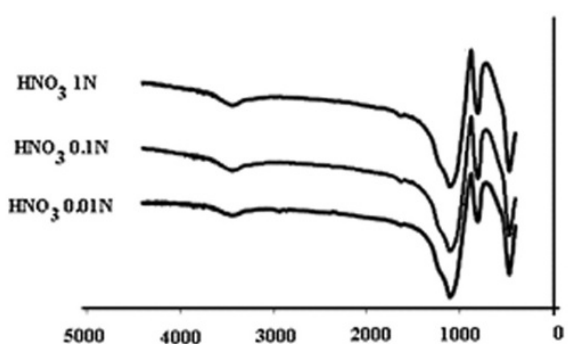

(d)

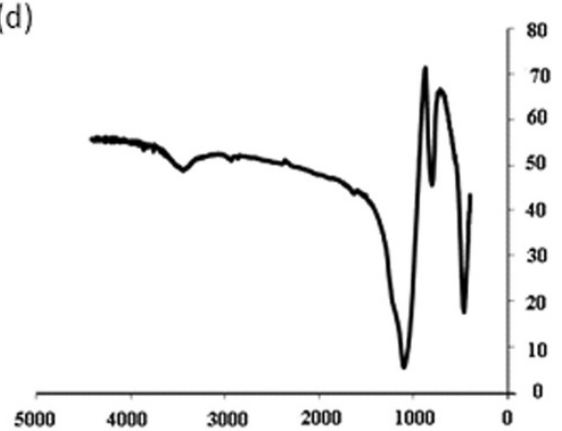

Figure $2 \mathrm{FTIR}$ spectra of RHA (burned at $700^{\circ} \mathrm{C}$ and soaking time is $\mathbf{2} \mathbf{~ h}$ ). (a) $\mathrm{RH}$ treatment with $\mathrm{HCl}$, (b) $\mathrm{RH}$ treatment with $\mathrm{HNO}_{3}$ with rate of heating $=10^{\circ} \mathrm{C} / \mathrm{min}$, (c) $\mathrm{RH}$ treatment with $\mathrm{HOAc}$ with rate of heating $=10^{\circ} \mathrm{C} / \mathrm{min}$, and (d) $\mathrm{RH}$ treatment with $\mathrm{H}_{2} \mathrm{O}$ with rate of heating $=$ $10^{\circ} \mathrm{C} / \mathrm{min}$. 


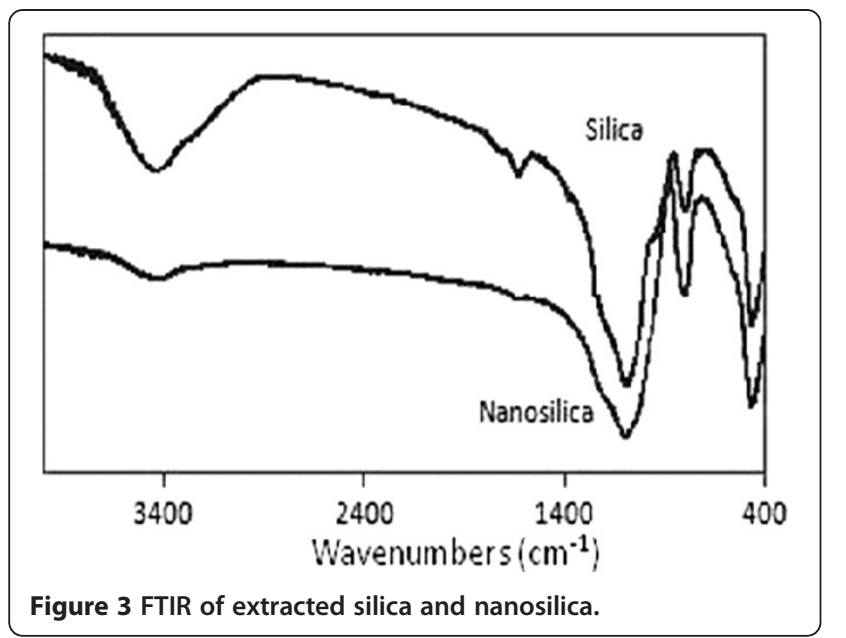

surface melting. Thus, the tendency of silica to retain carbon is eliminated, and white RHA is produced (Figure 1c,d). Lime reactivity was determined by a previously reported chemical method [23]. Table 2 gives the lime reactivity values of the ash samples prepared at different conditions. The RHA that was treated with $1.0 \mathrm{M}$ $\mathrm{HCl}$ and burned at $700^{\circ} \mathrm{C}$ at the rate of $10^{\circ} \mathrm{C} / \mathrm{min}$ and soaked in a programmable furnace for $2 \mathrm{~h}$ showed the maximum reactivity. Therefore, according to the results of Tables 1 and 2 and Figure 1, the above conditions are suitable for the preparation of highly purified RHA with high surface area. This white RHA was used for silica extraction and preparation of nanosilica.

Nanosilica was obtained from sodium silicate solution using precipitation method. The reaction is as follows:

$$
\underset{\text { Ash }}{\mathrm{SiO}_{2}}+\underset{\text { Caustic soda }}{2 \mathrm{NaOH}} \rightarrow \underset{\text { Sodium silicate Water }}{\mathrm{Na}_{2} \mathrm{SiO}_{3}}+\underset{\mathrm{H}_{2} \mathrm{O}}{\mathrm{S}_{\text {Wat }}}
$$

The silica particles were generated from the solution by adding sulfuric acid as catalyst. The acidic condition of $\mathrm{pH} 2$ indicates approximately the complete precipitation of silica from sodium silicate by the following reaction:

$$
\mathrm{Na}_{2} \mathrm{SiO}_{3}+\mathrm{H}_{2} \mathrm{SO}_{4} \rightarrow \mathrm{SiO}_{2}+\mathrm{Na}_{2} \mathrm{SO}_{4}+\mathrm{H}_{2} \mathrm{O}
$$

At a low silicate concentration and with the $\mathrm{pH}$ less than $8, \mathrm{Si}(\mathrm{OH})_{4}$ is the dominant species in its aqueous solution. At higher concentrations, the silanols, the $\mathrm{Si}(\mathrm{OH})$ groups, spontaneously polymerize to yield higher oligomers linked

Table 4 Content of carbon, hydrogen, and nitrogen of RH, RHA, and nanosilica at optimum conditions

\begin{tabular}{llll}
\hline & RH & RHA & Nanosilica \\
\hline C (\%) & 25.313 & 1.285 & 0.119 \\
H (\%) & 3.952 & 0.528 & 0.113 \\
N (\%) & 0.551 & 0.000 & 0.000 \\
\hline
\end{tabular}

Table 5 Properties of RHA and nanosilica

\begin{tabular}{lll}
\hline & RHA & Nanosilica \\
\hline$S_{\text {BET }}\left(\mathrm{m}^{2} / \mathrm{g}\right)$ & 153.1 & 623 \\
Pore volume $\left(\mathrm{cm}^{3} / \mathrm{g}\right)$ & 0.00650 & 0.02408 \\
Particle sizes $(\mathrm{nm})$ & Approximately $60^{\mathrm{a}}$ & 6 \\
Amorphous form $(\%)$ & 97.75 & 99.90 \\
\hline aFrom XRD. & &
\end{tabular}

by a disiloxy bond. Such a reaction is most favorable when one of the silanols is deprotonated to a $\mathrm{Si}^{-\mathrm{O}^{-}}$group. These oligomers grow into colloid-sized silica particles in which larger particles grow at the expense of smaller ones. At a higher $\mathrm{pH}$ (greater than 8), however, the much more concentrated silicate solution is stable. This is because disiloxy bonds undergo nucleophilic attacks by $\mathrm{OH}^{-}$via a five coordinated intermediate.

\section{Characterization}

After acid treatment and controlled combustion, 22.5\% of RHA was produced. The percentage of pure silica in the RHA, extracted silica, and nanosilica were $90.469 \%$, $96.529 \%$, and $98.801 \%$, respectively (Table 3 ). It is interesting to note that only $\mathrm{MgO}$ was detected in the extracted silica, and it was also present in a lower concentration in the nanosilica. Other impurities could be detected below the limit of quantification $<0.01 \%$ (or 0.1 $\mathrm{mg} / \mathrm{g}$ ). The color of both RHA and nanosilica was white (Figure 1d,e).

Chemical composition (wt.\%) as estimated after treatment of $\mathrm{RH}$ with $1.0 \mathrm{M} \mathrm{HCl}$, combustion at $700^{\circ} \mathrm{C}$ at rate of $10^{\circ} \mathrm{C} / \mathrm{min}$, and after $2 \mathrm{~h}$ of soaking. Also, traces of $\mathrm{P}, \mathrm{Cl}, \mathrm{Ni}, \mathrm{Cu}, \mathrm{Zn}, \mathrm{Pd}, \mathrm{W}$, and $\mathrm{Bi}$ were found in $\mathrm{RHA}$ and extracted silica

The FTIR spectra of almost all RHA samples gave typical bands of O-Si-O stretching (at 1,096 and $798 \mathrm{~cm}^{-1}$ )

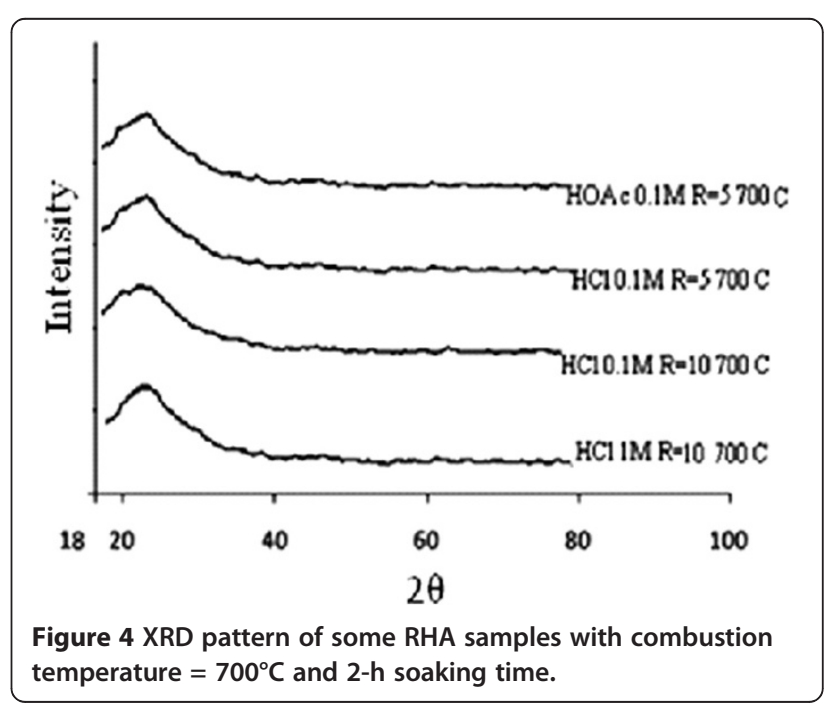




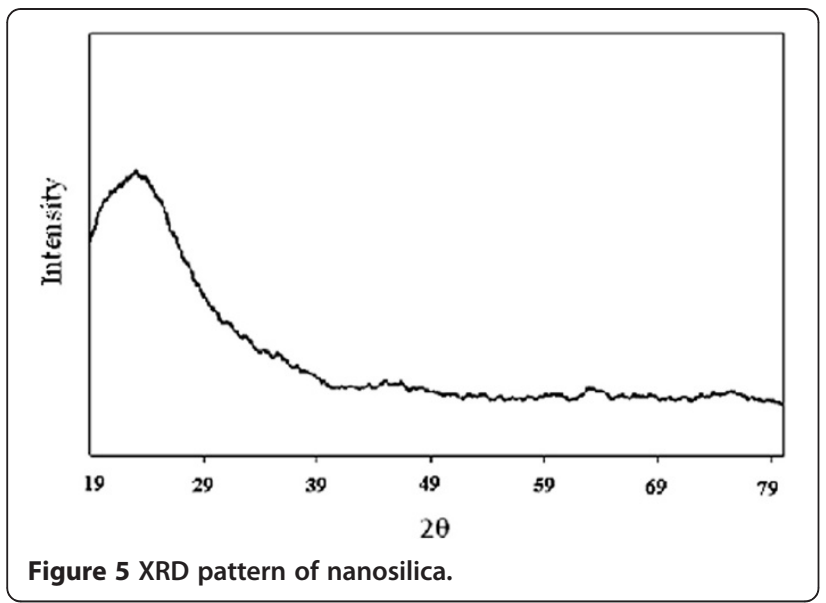

and bending vibrations (at $466 \mathrm{~cm}^{-1}$ ). The bands at 3,437 and $1,633 \mathrm{~cm}^{-1}$ corresponded to the $\mathrm{O}-\mathrm{H}$ stretching and bending vibrations (Figure 2). Figure 3 shows the results of the FTIR analyses of extracted silica and nanosilica. The peaks at 1,101 and $804 \mathrm{~cm}^{-1}$ are due to the $\mathrm{Si}-\mathrm{O}-\mathrm{Si}$ asymmetric and symmetric stretching modes, respectively. The band centered at $469 \mathrm{~cm}^{-1}$ is due to the bending frequency of Si-O-Si. A large broad band around $3,429 \mathrm{~cm}^{-1}$ is attributed to the presence of the $\mathrm{O}-\mathrm{H}$ stretching frequency for the silanol group and the remaining adsorbed water. A band around $1,630 \mathrm{~cm}^{-1}$ is assigned to the bending vibration of water molecules bound to the silica matrix. No peak was found between 2,800 and $3,000 \mathrm{~cm}^{-1}$. It means that there were no original organic compounds in the silica after controlled combustion and extraction. This result corresponds well with the carbon measurement by $\mathrm{CHN}$ analysis reported in Table 4. The FTIR spectra showed no significant changes in the peak position for extracted silica and nanosilica.

Silica with a high surface area is a good compound to be used as adsorbent or support for catalysts. Also, the reactivity of silica is directly related to its surface area. The BET-specific surface area and pore volume of RHA (at optimized conditions) and nanosilica are given in

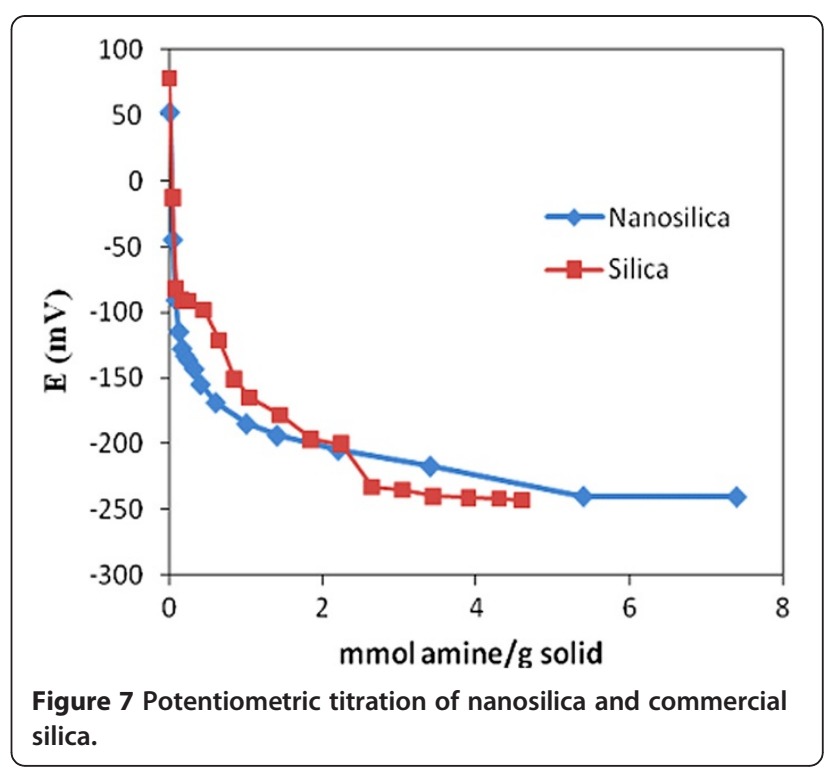

Table 5. A major contribution to the high surface area is that the organic matter has been broken up during the thermal decomposition of $\mathrm{RH}^{\prime}$, thus leaving a highly porous structure. The increasing pore volume in nanosilica confirms this phenomenon.

The evaluation of the amount of amorphous form of silica is very important. For this purpose, there are some specific methods in the literature $[24,25]$. One of them established that the degree of amorphous form of silica is estimated by the 'silica activity index', which is determined by calculating the percentage of valuable silica dissolved in an excess of boiling $4 \mathrm{M} \mathrm{KOH}$ in a 3-min extraction period [24]. This method was investigated for extracted silica and nanosilica, and the results were 99.7\% and 99.9\% amorphous form, respectively. For clarification, the XRD results were examined. Figures 4 and 5 show, from some samples of RHA prepared at different conditions and nanosilica present, a broad peak at $2 \theta=22^{\circ}$ associated with amorphous silica. The lack of sharp peaks indicates the absorbance of any ordered crystalline structure, confirming the results from the

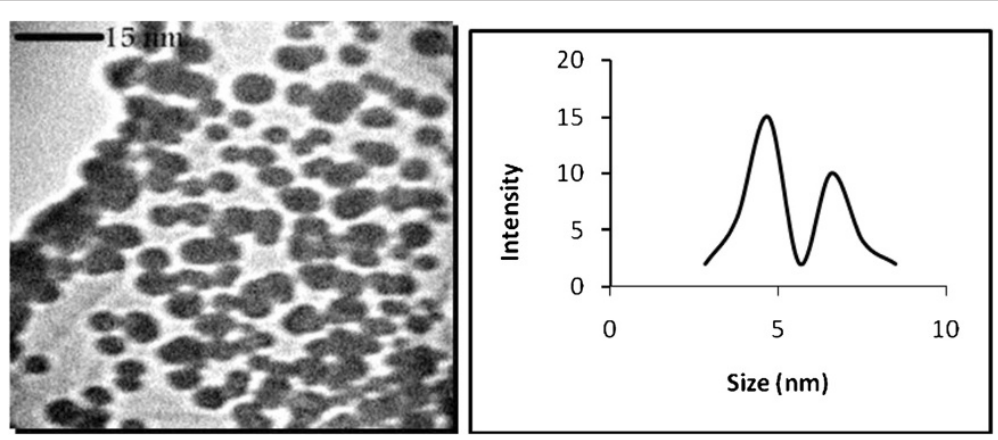

Figure 6 TEM image and diagram of particle size distribution of nanosilica particles. 
silica activity index and the lack of crystalline phase. Also, there are no peaks of carbon, porous or activated, which can be produced by heating $\mathrm{RH}$ at a relatively lower temperature when this phenomenon occurs due to the presence of potassium [26]. However, an acid treatment of the husk removed most of the potassium, and the ash became free of fixed carbon. The size of the particles was estimated by the half width of the peak $(\beta)$ using Scherer's formula:

$$
\mathrm{D}=\frac{\mathrm{K} \lambda}{\beta \operatorname{Cos} \theta}
$$

with $K=0.9 \mathrm{~nm}$ as a constant, $\lambda=1.542 \AA$ as wavelength of $\mathrm{Cu}-\mathrm{K} \alpha$, and $\beta$ in radian. By a manual evaluation of the XRD chart, the particle size of nanosilica was found to be about $7 \mathrm{~nm}$. Also, Figure 6 depicts the TEM micrograph of the nanosilica. The shape of the silica grains is spherical with an average particle size of $6 \mathrm{~nm}$, which is in agreement with the size estimated by Scherer's formula.

The milligrams of $\mathrm{CaO}$ to grams of nanosilica and RHA are represented in Table 3 for the comparison of lime reactivity. Lime reactivity of nanosilica is relatively high, indicating that the silica is reactive.

Acidity measurements of catalyst by means of potentiometric titration with $n$-butylamine were used to estimate its relative acid strength according to the two values: (1) $E_{\mathrm{i}}$ as initial potential and (2) number of acid sites (Figure 7). The initial electrode potential $\left(E_{\mathrm{i}}\right)$ indicates the maximum strength of the acid sites, and the value from which the plateau is reached (millimole amine per gram of solid) indicates the total number of acid sites that are present in the titrated solid [27]. The acidic strength of the solids can be classified according to the following range: $E_{\mathrm{i}}>100 \mathrm{mV}$ (very strong sites), $0<E_{\mathrm{i}}<100 \mathrm{mV}$ (strong sites), $-100<E_{\mathrm{i}}<0 \mathrm{mV}$ (weak sites), and $E_{\mathrm{i}}<-100 \mathrm{mV}$ (very weak sites). According to the potentiometric titration curve, both the commercial silica (Aerosil 300 silica) and the nanosilica presented strong acidic sites. However, nanosilica has a higher surface area and a higher number of surface acidic sites compared with commercial silica $(n=5.4$ and $2.6 \mathrm{mmol}$ amine/g solid, respectively).

\section{Conclusions}

Acid treatment of $\mathrm{RH}$ followed by thermal combustion under controlled conditions gave $22.50 \%$ ash of which $90.469 \%$ was silica. At optimized conditions, a nanosized, highly purified silica (98.8 mass percentage) was produced with a high surface area, high reactivity, and 99.9\% in amorphous form. This nanosilica showed strong and a large number of acidic sites in comparison with commercial silica, making it a good support for catalysts. Considering the availability of $\mathrm{RH}$ worldwide, this study shows that economic technology can be used by rice-producing companies to produce highly effective silica and to reduce the environmental impact of the usually uncontrolled burning of the by-products of the industry, namely $\mathrm{RH}$. This is particularly relevant to an agro-based country, which is still importing micro- and nanosilica for some applications.

\section{Competing interests}

The authors declare that they have no competing interest.

\section{Authors' contributions}

ER conceived the study and did the major part of the article with SS. MF carried out the X-ray diffractions. MS did some of the characterizations. All authors read and approved the final manuscript.

\section{Acknowledgements}

The authors wish to thank the Razi University Research Council and Kermanshah Oil Refining Company for their support on this work, as well as Ellen Vuosalo Tavakoli (University of Mazandaran) for editing the English text.

\section{Author details}

${ }^{1}$ Faculty of Chemistry, Razi University, Kermanshah 67149, Iran. ${ }^{2}$ School of Pharmacy, Mashhad University of Medical Sciences, Mashhad, Iran.

Received: 8 October 2012 Accepted: 8 October 2012

Published: 24 October 2012

\section{References}

1. Rahman, IA, Ismail, J, Osman, H: Effect of nitric acid digestion on organic materials and silica in rice husk. J. Mater. Chem. 7, 1505 (1997)

2. Zhang, MH, Malhotra, VM: High-performance concrete incorporating rice husk ash as a supplementary cementing material. ACI Mater. J. 93, 629 (1996)

3. Barkakati, P, Bordoloi, D, Borthakur, PC: Paddy husk as raw material and fuel for making Portland cement. Cem. Concr. Res. 24, 613 (1994)

4. Key, PH, Sands, D, Schlaf, M, Walton, CD, Anthony, CJ, Brunson, KM, Uren, MJ: Infra-red reflectivity of ion-implanted and pulsed excimer laser irradiated 4H-SiC. Thin Solid Films 364, 200 (2000)

5. Siqueira, EJ, Yoshida, IVP, Pardini, LC, Schiavon, MA: Preparation and characterization of ceramic composites derived from rice husk ash and polysiloxane. Ceram. Int. 35, 213 (2009)

6. Sun, L, Gong, K: Silicon-based materials from rice husks and their applications. Ind. Eng. Chem. Res. 40, 5861 (2001)

7. Ghosh, TB, Nandi, KC, Acharya, HN, Mukherjee, D: X-ray photoelectron spectroscopic analysis of amorphous silica - a comparative study. Mater. Lett. 12, 175 (1991)

8. Conradt, R, Pimkhaokham, P, Leela-Adisorn, U: Nano-structured silica from rice husk. J. Non-Cryst. Solids 145, 75 (1992)

9. Real, C, Alcala, MD, Criado, JM: Preparation of silica from rice husks. J. Am. Ceram. Soc. 79, 2012 (1996)

10. Martin, J: The desilification of rice hull and a study of the products obtained. Lousiana State University, MS thesis (1938)

11. Yalçin, N, Sevinç, V: Studies on silica obtained from rice husk. Ceram. Int. $27,219(2001)$

12. Chandrasekhar, S, Pramada, PN, Praveen, L: Effect of organic acid treatment on the properties of rice husk silica. J. Mater. Sci. 40, 6535 (2005)

13. Chandrasekhar, S, Pramada, PN, Majeed, J: Effect of calcination temperature and heating rate on the optical properties and reactivity of rice husk ash. J. Mater. Sci. 41, 7926 (2006)

14. Chandrasekhar, S, Pramada, PN, Raghavan, P, Satyanarayana, KG, Gupta, TN: Microsilica from rice husk as a possible substitute for condensed silica fume for high performance concrete. J. Mater. Sci. Lett. 21, 1245 (2002)

15. Umeda, J, Kondoh, K: High-purification of amorphous silica originated from rice husks by combination of polysaccharide hydrolysis and metallic impurities removal. Ind. Crop. Prod. 32, 539 (2010)

16. Pijarn, N, Jaroenworaluck, A, Sunsaneeyametha, W, Stevens, R: Synthesis and characterization of nanosized-silica gels formed under controlled conditions. Powder Technol. 203, 462 (2010) 
17. El-Hosiny, Fl, Abo-El-Enein, SA, Helmy, IM, Khalil, KA: Effect of thermal treatment of rice husk ash on surface properties of hydrated Portland cement-rice husk ash pastes. J. Therm. Anal. 48, 809 (1997)

18. Mochidzuki, K, Sakoda, A, Suzuki, M, Izumi, J, Tomonaga, N: Structura behavior of rice husk silica in pressurized hot-water treatment processes. Ind. Eng. Chem. Res. 40, 5705 (2001)

19. Chandrasekhar, S, Satyanarayana, KG, Pramada, PN, Raghavan, P, Gupta, TN: Review processing, properties and applications of reactive silica from rice husk - an overview. J. Mater. Sci. 38, 3159 (2003)

20. Tomozawa, M, Kim, DL, Lou, V: Preparation of high purity, low water content fused silica glass. J. Non-Cryst. Solids 296, 102 (2001)

21. Tanner, PA, Yan, B, Zhang, H: Preparation and luminescence properties of sol-gel hybrid materials incorporated with europium complexes. J. Mater. Sci. 35,4325 (2000)

22. Wu, G, Wang, J, Shen, J, Yang, T, Zhang, Q, Zhou, B, Deng, Z, Bin, F, Zhou, D, Zhang, F: Properties of sol-gel derived scratch-resistant nano-porous silica films by a mixed atmosphere treatment. J. Non-Cryst. Solids 275, 169 (2000)

23. Rao, GR, Sastry, ARK, Rohatgi, PK: Nature and reactivity of silica available in rice husk and its ashes. Bull. Mater. Sci. 12, 469 (1989)

24. Payá, J, Monzó, J, Borrachero, MV, Mellado, A, Ordoñez, LM: Determination of amorphous silica in rice husk ash by a rapid analytical method. Cement Concrete Res. 31, 227 (2001)

25. Mehta, PK: Siliceous ashes and hydraulic cements prepared therefrom. (1973). Belgian Patent 802909. July 1973

26. Krishnarao, RV, Subrahmanyam, J, Kumar, TJ: Studies on the formation of black particles in rice husk silica ash. J. Eur. Ceram. Soc. 21, 99 (2001)

27. Rafiee, E, Joshaghani, M, Eavani, S, Rashidzadeh, S: A revision for the synthesis of $\beta$-enaminones in solvent free conditions: efficacy of different supported heteropoly acids as active and reusable catalysts. Green Chem. 10, $982(2008)$

doi:10.1186/2228-5326-2-29

Cite this article as: Rafiee et al:: Optimization of synthesis and characterization of nanosilica produced from rice husk (a common waste material). International Nano Letters 2012 2:29.

\section{Submit your manuscript to a SpringerOpen ${ }^{\circ}$ journal and benefit from:}

- Convenient online submission

- Rigorous peer review

- Immediate publication on acceptance

- Open access: articles freely available online

- High visibility within the field

- Retaining the copyright to your article 